\title{
Some features of rural economic diversification in mining regions
}

\author{
Tatyana Yakushnina ${ }^{1}$ \\ ${ }^{1}$ T.F. Gorbachev Kuzbass State Technical University, 650000 Kemerovo, 28 Vesennya st., Russian \\ Federation
}

\begin{abstract}
Diversification is one of the main directions for improving the sustainability of rural development, as well as technological renewal of industries and certain sectors of the rural economy. The need to diversify the rural economy is due to the peculiarities of agricultural production, such as seasonality, low profitability of agricultural work, low cost of production. Diversification of the rural economy will make it possible to move from a predominantly monofile model of the rural economy to a multispectral one.
\end{abstract}

\section{Introduction}

Rural areas play an important economic role because of the large amount of both sociodemographic and natural resources in rural areas, which could contribute to economic growth in rural areas as well as in the economy as a whole. At present, however, one of the problems in rural areas is the uneven economic development of rural areas. While some regions are experiencing sustained economic growth, in contrast, production are declining, population is falling, which could cause their degradation.

In order to address these challenges, a number of countries, both developed and developing, are being encouraged to move towards a diversified rural economy model, which will address a number of problems in rural areas, namely rural employment, rural quality and standard of living, rural economic and food security, and nearby small towns. The need to diversify the rural economy, in our view, is also due to the feature of agricultural production such as seasonality, the low level of return on agricultural labour and the low cost of production.

Therefore, the "Concept of Sustainable Development of Rural Areas of the Russian Federation for the Period up to 2020" considers diversification as one of the main directions for improving the sustainability of rural development, as well as technological renewal of industries and certain sectors of the rural economy. However, the concept highlights the problem itself, but does not offer an integrated approach that could provide a basis for the systematic development of new directions for rural development.

\section{Materials and Methods}

Some foreign authors use a special term to reflect the combination of diverse activities in rural areas. Thus, Haggblade S. et al. [4] applies the concept of "non-agricultural 
economy" (rural areas). It includes many non-agricultural economic activities manufacturing, mining, construction, trade, infrastructure, transportation, tourism and other services. The heterogeneity of the rural economy makes it necessary to consider the diversification of the rural economy as a complex multi-level and mutually agreed process, covering both the macro-level, the meso-level and the micro-level. Analysis of special literature has shown that there is no consensus among researchers as yet on what to consider diversification in relation to rural economies. The diversity of interpretations, in our view, is because the various works of researchers focus on different elements and levels of expansion of the necessary diversity. For example, a number of instruments on rural development programming address diversification primarily as a variety of individual farm activities that generate income for the household. At the same time, it was stressed that agricultural work on the farm is excluded from diversification, and special attention is paid to the fact that the direct use of the resources of the farm, i.e. land, buildings, equipment and equipment, is a prerequisite for the process of diversification of the population's farms [1].

The rural economy is "a system of industries and activities that includes, apart from agriculture and forestry, extractive and processing industries, rural services, and infrastructure."

The concept of infrastructure received a comprehensive study in foreign literature in the 40-50 yeas of the last century. P. Rosenstein-Rodan, in his work, emphasized the special importance of "social overhead" in industries such as energy, transport, communications, etc., to accelerate and increase the return on subsequent investments in the economy, which he called "framework" or "infrastructure" [15; 16]. Similarly, the early work of A. O. Hirschmann [5] emphasizes the high role of infrastructure as a driving force for economic development, but later, in exploring infrastructure projects, the author points out that it is wrong to view infrastructure formation as a key tool for economic development without corresponding demand, which can lead to significant damage [6]. However, infrastructure investment in the development of the territory and market has a major role to play today. With this approval, work on infrastructure investment research begins $[3 ; 10 ; 12 ; 17 ; 19]$. There is a symbiosis of technologies and infrastructure under the general term "infratechnology" [8], which means both methods of testing new technologies and the formation of a database for research on various types of activities. The efficiency of investments in infrastructure projects (including infratechnologies) is higher for the state than for the private sector $[3 ; 10]$. Current overseas research on infrastructure investment in the Territory aims to develop an integrated approach to developing a sustainable infrastructure investment system that takes into account both the economic, social, and environmental impacts of such investment. T. D. Foxon notes that infrastructure systems include physical and social networks, which mediate between flows of material resources and the provision of services for households and enterprises [12]. D. T. Scott emphasizes that there is a lack of investment in new technologies in a market that lacks appropriate infrastructure [17]. Research on the importance of infrastructure investment for the development of the economy at the macro, mesoia micro level is enshrined by a number of normative acts and is investigated by Russian scientists. The Urban Planning Code of the Russian Federation identifies the concept of engineering, transport and social infrastructures as tools for ensuring the sustainable development of the territory of N. A. Ivanov, considering the concept of "infrastructure," conducts a comparative characteristic of fifteen definitions and concludes that infrastructure is a set of industries designed to create and provide organizational, economic, social and legal conditions for the normal functioning of the economy and ensure the quality of life of people [8]. The analysis of the definitions of the concept under consideration showed that the main elements of infrastructure in the scientific literature include material and organizational and legal 
conditions, material and technical means, a set of enterprises, organizations and institutions, types and spheres of activity, as well as a set of interrelated service structures. These elements ensure the normal, free or (less frequently) effective functioning of the economy. The only thing that most definitions agree on is that the ultimate recipient of infrastructure development remains the person (population), and the degree of infrastructure involvement in the process may vary. Thus, social infrastructure, represented by housing and communal services, education, health care, social security, etc., has a direct impact on the processes of life of the population, while productive infrastructure affects indirectly through the development of the economic basis for improving the standard of living of the population.

\section{Results and Discussion}

The basic instrument for strategic planning of the diversification process is the integrated investment plan for the modernization of the Territory. The development of a comprehensive investment plan makes it possible to form an application for State funding for the Territory 's diversification and development programmer. However, these funds are exclusively for infrastructure projects. The latter determines the relevance of the formation of infrastructure for the diversification of the Territory 's economy.

At the present stage, the mono-relevant territories of Russia are experiencing a development crisis (economic, social and social-civil) caused by the outdated structure of local production, wear and tear of equipment, networks and systems, relatively low (compared to Western countries) qualification of the employed population, social passivity of most citizens, weakness of local budgets. The main challenges to be addressed are: 1) the high rate of unemployment moving into stagnant unemployment; 2) insufficient innovative activity of local enterprises; 3) limited functional orientation of local production; 4) increased degree of risks of the economy of the Territory; 5) immaturity of civil society relations.

At present, mono-profile territories are at the point of bifurcation, i.e. the choice of the path of their development. Two main options can be mentioned: the preservation of the current situation with all the resulting consequences or the launch of a mechanism of diversification and radical modernization, which will make mono city economically and socially different after a certain period of time [2].

Harmonization of interests of participants in the process of diversification of rural economy is one of the most important issues, as it affects almost all stages of development and implementation of diversification projects: Horizontal and vertical harmonization at the stage of setting goals and targets, as well as at the stages of determining development priorities, collecting potential ideas and attracting potential investors, selecting projects and developing a development program, implementing projects and a program of diversification of the territory, assessing the effectiveness of the achieved results (from the position of different actors will differ), monitoring, control, as well as developing corrective measures. The degree of harmonization of the interests of the participants in the diversification process has a direct impact on the effectiveness of the diversification process in rural areas. The study of approaches to the harmonization of interests of different groups of persons is based on the current theory of stakeholders developed by foreign authors [1-3] and actively applied to territorial development, interaction between industrial enterprises and universities [4], as well as other participants on the example of the process of diversification of the economy of the rural territory [5-7].

One of the first works to start studying the problems of mono industrial territory was the research of I. Harold [5] and P. Landis [9] in the 1930s, devoted to coal industrial territories, the need for modernization of which is overdue by the second half of the last century [10-12]. In Russia, the problems of development of mono-relevant territories in 
modern conditions are a pressing issue in all regions of the country. Currently, there are 66 single towns of various profiles in the Siberian Federal District. The undisputed leader in the number of single towns is Kemerovo Oblast, where out of 49 cities and urban settlements, 24 are single towns. At the same time, with the risk of deterioration of the socio-economic situation in the Kemerovo region - 16 territories.

At the same time, with all attention to the problems of single towns and taking into account all ways to solve them - from radical to the mildest and least painful - it is a matter of very distant perspective. There remain psychology of residents, traditions, inertia of previous stages of development of rural territory. In addition, significant financial resources and competent State and municipal policies are needed. Important policy decisions that directly determine the Territory 's future are often beyond the capacity of local governments to influence these decisions. Therefore, there is an objective need for an agreement (partnership, cooperation) in the system "federal power - regional power - municipal power - business" on concrete actions and measures of strategic importance for mono-specialized territory that should be taken. The system of public-private partnership is the key to solving many problems of mono-specialized territory. The federal authorities finance specific investment projects that create new knowledge-intensive jobs and diversify rural economies. Regional authorities can finance the development of infrastructure, in particular transport. The municipality creates an extensive system of services, increases the share of processing industries, finances social infrastructure, develops small entrepreneurship, determines points of economic and social development (growth), forms conditions for respect for work. The municipality is responsible for the establishment of a guarantee system for investment activities; Definition of clear and understandable procedures for opening a new enterprise; Establishment of clear rules for land use, removal of land for construction; Reasonable regulation of prices and tariffs for services; Granting tax incentives; Formation of attractive appearance (image) of the territory; Creation of a data bank that reveals investment and innovation potential; Information support of the project, etc. Business represented by corporations (city-forming enterprises) should first of all look for ways to increase innovation activity, determine sources of investments, justify opportunities of enterprise restructuring, solve problems of introduction of new technologies. At the same time, business managers should make greater use in practice of the provisions of the "Manifesto on the Moral Code of the Manager," adopted in Davos in 1973, which states: "The professional task of the management of the enterprise is to serve customers, employees, investors and society. Enterprise profit is a necessary means but not the ultimate goal of enterprise management. "

\section{Conclusion}

The main resource of mono profile territories is not the assets of the city-forming enterprise, but the cash population. However, at present in Russia as a whole there are no clearly developed methods of activation of this resource, disclosure of its potential. If programmers of reform of mono-relevant territories are launched without taking into account the intensification of human resources, especially the most creative groups of the population, the inefficient use of local resources can be predicted with a high degree of probability.

Thus, the importance of diversification, for the rural economy, is primarily that it will allow the transition from a predominantly monofile model of the rural economy to a multifunctional one, that is, a multi-sectoral one. This implies the creation in rural areas of as many economic forms and activities as possible to meet the employment needs of the population. 


\section{Reference}

1. Briefing European Parliamentary Research Service. Farm diversification in the EU. URL: http://www.europarl.europa.eu/RegData/etudes/

2. A. Bebbington, L. Hinojosa, D.H. Bebbington, M.L. Burneo, X. Warnaars, Development and Change, 39:6, 887-914 (2008)

3. Emile A. Theoretical Approach of Public Infrastructures' Role in The Economic Growth // Indian Journal of Applied Research. 2016. Vol. 6, № 7. P. 464-470.

4. S. Haggblade, P.B., H. Reardon, Transforming the rural non-farm economy: Opportunities and threats in the developing world (Johns Hopkins University Press, Baltimore, 2007)

5. I. Harold, Settlement and the Mining Frontier, in Settlement and the Forest Frontier in Eastern Canada (Toronto, Macmillan of Canada, 1936)

6. A.O. Hirschman, Development projects observed (Brookings Institution Press, New York, 2011)

7. A.O. Hirshman, The Strategy of Economic Development (Yale University Press, Washington, 1958)

8. L.E. Karlsson, Evidence \& Policy: a Journal of Research, Debate and Practice, 3, 433454 (2017)

9. P.H. Landis, Three iron mining towns: a study in cultural change (Edwards brothers, Ann Arbor, 1938)

10. A.N. Link, Scientometrics, 36, 3, 325-342 (1996)

11. D. Littlewood, Journal of business ethics, 120:1, 39-63 (2014)

12. T. J. Foxon, Infrastructure Complexity, 2:1, 1-13 (2015)

13. S. Miles, Journal of Business Ethics, 142:3, 437-459 (2017)

14. J. Moriarty, Business Ethics Journal Review, 4:8, 47-52 (2016)

15. P.N. Rosenstein-Rodan, The Review of Economics and Statistics, 1, 107-138 (1961)

16. P.N. Rosenstein-Rodan, Notes on the theory of the 'big push' (Palgrave Macmillan, London, 1961)

17. J.T. Scott, The Journal of Technology Transfer, 24:1, 37-54 (1999)

18. M. Tonts, P. Plummer, M. Lawrie, Journal of Rural Studies, 28:3, 288-301 (2012)

19. K. Young, J. W. Hall, Infrastructure Complexity, 2:1, 1-18 (2015) 